\title{
PENENTUAN LOKASI TITIK BOR AIR TANAH BERDASARKAN METODE TAHANAN JENIS 2D DI DESA SUBUR MAKMUR KABUPATEN KOTABARU, KALIMANTAN SELATAN
}

\author{
Rudy Hendrawan Noor ${ }^{1)}$ dan Ishaq ${ }^{1)}$ \\ ${ }^{1}$ Jurusan Teknologi Pertambangan, Akademi Teknik Pembangunan Nasional (ATPN) Banjarbaru, Jl. Taman Gembira \\ Barat No.14 GuntungPaikat, kodepos 70711 \\ Email; rudyhendrawan28@gmail.com; ishaqitb14@gmail.com
}

\begin{abstract}
Subur Makmur Village is an area where the availability of clean water is difficult, especially during the dry season. One of the sources of water that can be used by the villagers is groundwater. However, to obtain groundwater, it is necessary to drill wells and investigate the aquifer layer first. This study aims to obtain an overview of the subsurface layers based on the resistivity properties of the rock, so that the aquifer layer can be identified and can determine the exact location of the drill point in the prospective aquifer position that may be encountered. The geoelectric method is the most efficient method for detecting aquifer layers. It uses two types of configurations, namely, the Wenner and Wenner-Schlumberger configurations where the number of geoelectric paths is one path. The length of the track used is 540 meters, the number of electrodes is 28 with the spacing between the electrodes is 20 meters. The resistivity cross section for both configurations, obtained resistivity values of 11 - 140 Ohm meters. Composed of 2 (two) rock units, namely graywacke sandstone rock units. Consists of graywacke sandstones with claystone inserts. Density value $\geq$ $40 \mathrm{Ohm}$ meter. Hydraulic properties, small porosity, small permeability, the potential for groundwater in this unit is small. The position of this unit is at a depth of $40 \mathrm{~m}$. In the cross section, the resistivity is yellow - red. The second rock unit comprising this trajectory is the alteration claystone unit consisting of claystone containing bolders of sandstone / igneous rock. Resistivity value $\leq 40 \mathrm{Ohm}$ meter. The position of this unit is on the Surface to a depth of $40 \mathrm{~m}$. Hydraulic properties, large porosity with very small permeability, the potential for groundwater is very small. In the cross section of this unit resistivity are colored dark blue, blue and green. From the resistivity cross section, it can be determined the position of the borehole which is effectively located in the length range of the trajectory between 360 - 420 meters.
\end{abstract}

Keywords: subur makmur, groundwater, wenner, wenner-schlumberger

\section{PENDAHULUAN}

Kebutuhan air bersih merupakan kebutuhan primer yang harus dipenuhi oleh setiap mahluk hidup, terutama manusia. Selain untuk kebutuhan konsumsi (air minum) juga dapat digunakan pada aktivitas penunjang lainnya. Desa Subur Makmur merupakan daerah yang ketersediaan air bersih yang sulit terutama pada musim kemarau. Untuk memenuhi kebutuhan akan air bersih penduduk memanfaatkan sumur gali yang ada di desa tersebut, namun pemanfaatannya hanya ketika musim hujan, ketika musim kemarau maka air sumur akan surut bahkan keruh. Ketika kondisi tersebut terjadi maka sulit untuk penduduk desa memenuhi kebutuhan air bersih, terutama untuk kebutuhan konsumsi air minum.

Salah satu sumber air yang dapat dimanfaatkan oleh penduduk desa subur makmur adalah air yang bersumber dari tanah atau air tanah. Namun untuk memperoleh air tanah ini diperlukan penyelidikan terlebih dahulu, karena tidak semua bawah permukaan tanah meiliki lapisan akuifer (lapisan mengandung air). Selain penyelidikan lapisan akuifer, untuk memanfaatkan air tanah bawah permukaan umumnya menggunakan sumur bor yang harus menembus lapisan akuifernya. 
Menurut Bisri tahun 1991, ada beberapa metode penyelidikan untuk memperoleh lapisan akuifer, diantaranya: metode geologi, metode gravitasi, metode magnit, metode seismik, dan metode geolistrik. Dari metode-metode tersebut, metode geolistrik merupakan metode yang banyak sekali digunakan dan hasilnya cukup baik. Metode geolistrik didasari adanya perbedaan tahanan jenis masing-masing lapisan batuan bawah permukaan yang diinjeksikan arus listrik. Lapisan yang mengandung air akan memiliki nilai tahanan jenis yang lebih rendah dibandingkan dengan lapisan yang kering.

Sumur bor adalah metode yang paling umum digunakan untuk memperoleh air tanah dari lapisan akuifer. Penentuan letak titik atau posisi sumur bor akan mempengaruhi besar kecilnya air tanah yang dapat dimanfaatkan. Bahkan tidak jarang pengeboran sumur bor tidak menghasilkan, dalam artian pemboran sumur tidak menembus lapisan akuifer. Maka dari itu, penentuan titik sumur bor diawali dengan penyelidikan bawah permukaan dengan metode tahanan jenis yang nantinya diharapkan dapat menjadi referensi untuk penentuan letak titik sumur bor.

Penelitian ini bertujuan untuk memperoleh gambaran lapisan-lapisan bawah permukaan berdasarkan sifat tahanan jenis batuan atau formasi batuan di bawah permukaan desa subur makmur, sehingga dapat diidentifikasi lapisan akuifernya. Berdasarkan hasil tersebut dapat dilakukan penentuan lokasi titik bor secara tepat pada posisi akuifer prospektif yang mungkin dijumpai, dan selanjutnya dapat dilakukan pengembangan dengan cara melaksanakan pengeboran sumur bor.

\section{METODE PENELITIAN}

Lokasi penelitian ini terletak di Desa Subur Makmur Kecamatan Pulau Laut Barat Kabupaten Kotabaru Kalimantan Selatan. Gambar 1, merupakan peta lokasi penelitian.

Jenis data yang digunakan berupa data primer yang diukur langsung dilapangan berupa data geolistrik tahanan jenis. Menggunakan dua jenis konfigurasi yaitu, konfigurasi wenner dan wennerschlumberger dimana jumlah lintasan geolistriknya berjumlah satu lintasan. Panjang lintasan yang digunakan adalah 540 meter jumlah elektroda sebanyak 28 buah dengan spasi antara elektroda adalah 20 meter. Setiap elektroda di ukur koordinatnya menggunakan GPS (Globale Position System) sehingga dapat dijadikan sebagai faktor koreksi kedalaman permukaan hasil analisis data geolistrik. Dua konfigurasi digunakan sebagai pembanding dan melihat efektivitas dari kedua konfigurasi.

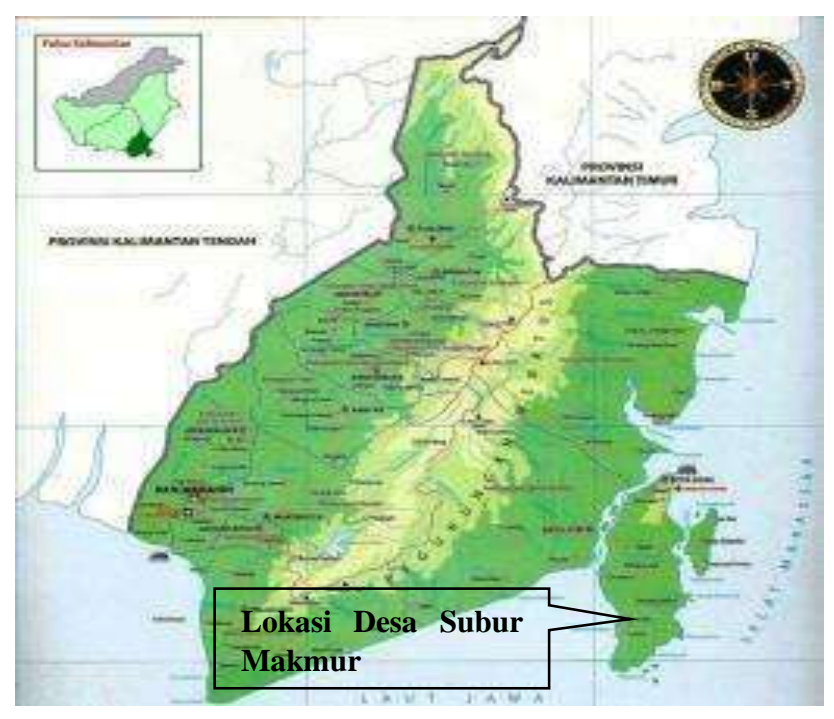

Gambar 1. Peta Lokasi Penelitian dan lintasan Geolistrik

Alat yang digunakan untuk pengambilan data geolistrik yaitu Supersting Rl/IP yang akan menghasilkan nilai tahanan jenis masing-masing lapisan batuan yang selanjutnya akan diolah lebih lanjut dengan menggunakan software AGISSAdmin.

Hasil analisis yang diperoleh berupa nilai tahanan jenis masing-masing lapisan batuan akan diintrepretasikan menggunakan referensi tahanan jenis.

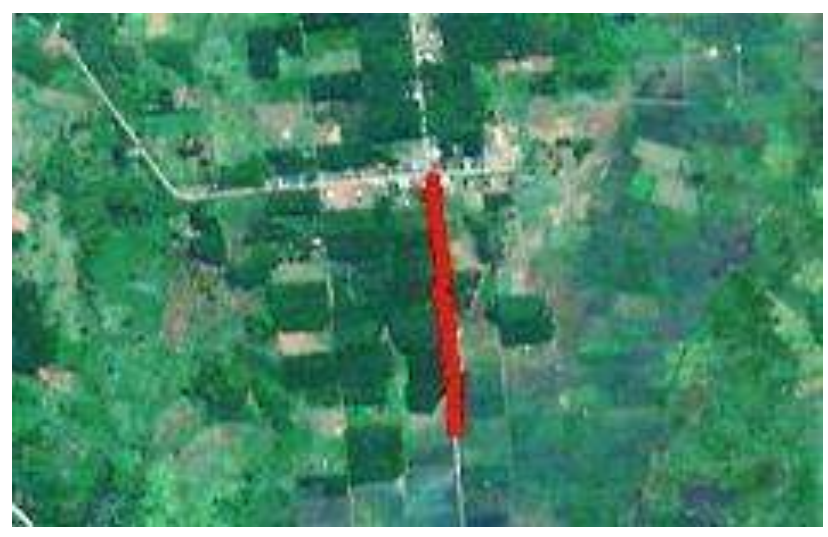

Gambar 2. Lintasan dan posisi elektroda geolistrik 
Sebagai faktor koreksi, dilakukan analisis berdasarkan keadaan geologi dan hidrogeologi daerah setempat untuk menentukan lokasi titik pemboran sumur bor yang prospek.

\section{Geolistrik Tahanan Jenis}

Metode geolistrik merupakan metode yang digunakan untuk mempelajari sifat aliran listrik di dalam bumi dengan cara mendeteksinya di permukaan bumi (Hendrajaya, 1990). Prinsip kerja metode geolistrik dilakukan dengan cara menginjeksikan arus listrik ke permukaan tanah melalui sepasang elektroda dan mengukur beda potensial dengan sepasang elektroda yang lain. Hasil pengukuran arus dan beda potensial untuk setiap jarak elektroda tertentu, dapat ditentukan variasi harga hambatan jenis masing-masing lapisan di bawah titik ukur (Rochman, dkk. 2017).

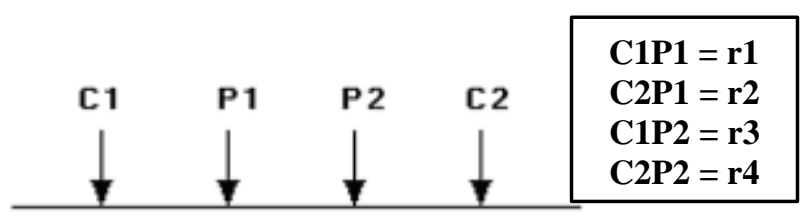

Gambar 3. Posisi elektroda pengukuran tahanan jenis

Harga resistivitas yang didapatkan merupakan resistivitas semu. Persamaan resistivitas semu:

$\rho_{a}=K \frac{\Delta V}{I}$

$\mathbf{V}=$ beda potensial $(\mathrm{mV})$

I $=\operatorname{arus}(\mathrm{mA})$

dengan:

$K=\frac{2 \pi}{\left(\frac{1}{r_{1}}-\frac{1}{r_{2}}\right)-\left(\frac{1}{r_{3}}-\frac{1}{r_{4}}\right)}$

dimana $\mathrm{K}$ adalah faktor geometri yang merupakan besaran koreksi letak kedua elektroda potensial terhadap elektroda arus (Reynolds, 1997).

\section{Konfigurasi Wenner}

Di antara beberapa konfigurasi, wenner memiliki kekuatan sinyal terkuat. Hal ini sangat membantu jika survei dilakukan di area dengan noise yang tinggi. Konfigurasi wenner relatif sensitif terhadap perubahan vertikal dalam resistivitas bawah permukaan tanah. Namun, kurang sensitif terhadap perubahan horizontal resistivitas bawah permukaan.
Secara umum, Wenner bagus dalam pendeteksian perubahan vertikal (yaitu struktur horizontal), tetapi relatif tidak sensitif dalam mendeteksi perubahan horizontal (yaitu struktur vertikal yang sempit).

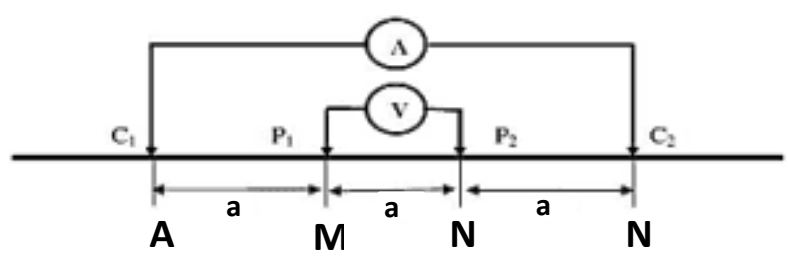

Gambar 4. Elektroda Konfigurasi Wenner

Faktor geometri dari konfigurasi wenner adalah:

$K=\mathbf{2} \pi a$

dengan $a$ adalah jarak antara elektroda.

\section{Konfigurasi Wenner-Shclumberger}

Konfigurasi ini merupakan gabungan antara Wenner dan Schlumberger dimana cukup sensitif terhadap horizontal (untuk nilai "n" rendah) dan struktur vertikal (untuk nilai "n" tinggi). Kekuatan sinyal lebih lemah dari Wenner, sehingga menjadi pertimbangan jika survei dilakukan di area dengan noise yang tinggi.

Konfigurasi ini adalah konfigurasi dengan sistem aturan spasi yang konstan dengan catatan faktor pembanding " $n$ " untuk konfigurasi ini adalah perbandingan jarak antara elektroda AM dengan jarak antara MN seperti pada Gambar 5. Jika jarak antara elektroda potensial MN adalah a maka jarak antar elektroda arus (A dan B) adalah 2na + a.

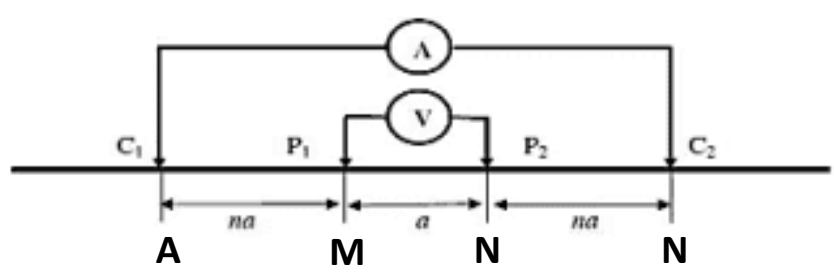

Gambar 5. Pengaturan Elektroda Konfigurasi Wenner-Schlumberger

Faktor geometri dari konfigurasi WennerSclumberger adalah :

$K=n(n+1) \pi a$

dengan

$a$ adalah jarak antara elektroda M dan N (Utiya, dkk, 2015). 


\section{Tahanan Jenis Air Tanah}

Salah satu metode survei Geofisika yang lazim digunakan untuk penelitian sumber air tanah adalah metode Geolistrik Tahanan Jenis.

Metode ini memanfaatkan keragaman nilai resistivitas batuan bawah permukaan untuk mendeteksi struktur geologi atau formasi batuan bawah permukaan, sehingga dapat diterapkan untuk menduga keberadaan akuifer air tanah (Priyantari dan Wahyono, 2005). Potensi keberadaan air tanah dapat diketahui dengan mengidentifikasi formasi batuan dan struktur bawah permukaan berdasarkan variasi nilai resistivitas (Wijaya, 2015). Resistivitas air tanah bervariasi dari 10 hingga $100 \mathrm{ohm} \cdot \mathrm{m}$. tergantung pada konsentrasi garam terlarut (Loke, 2004).

\section{HASIL DAN PEMBAHASAN}

\section{Efektivitas Konfigurasi}

Dari penampang tahanan jenis (Gambar 8), didapatkan nilai yang paling rendah $11 \mathrm{Ohm}$ meter yang paling tinggi $140 \mathrm{Ohm}$ meter untuk pendugaan geolistrik dengan susunan wenner-schlumberger dan susunan wenner. Tampak terlihat dari hasil analisis perbedaan distribusi nilai tahanan jenis yang membentuk lapisan-lapisan batuan. Hasil analisis pada susunan konfigurasi wenner-schlumberger menampilkan hasil nilai tahanan jenis bawah permukaan yang membentuk degradasi warna spotspot atau bolder, sedangkan pada konfigurasi wenner lebih sedikit muncul spot-spot nilai tahanan jenis. Jika dilihat dari hasil RMS (root mean square) nilai konfigurasi wenner-schlumberger adalah 3,97\% sedangkan pada konfigurasi wenner bernilai $2,01 \%$. Hal ini mengindikasikan bahwa konfigurasi wenner memiliki akurasi lebih baik dari konfigurasi wennerschlumberger.

Secara visual sangat jelas terlihat konfigurasi wenner lebih menampakkan adanya lapisan-lapisan bawah permukaan, sehingga nantinya akan mempermudah dalam intrepretasi lebih lanjut.

\section{Litologi}

Secara geologi berdasarkan ploting lokasi pada peta geologi, daerah pengukuran berada pada Formasi Tanjung (Tet). Formasi ini disusun oleh batupasir kwarsa dan batulempung dengan sisipan batubara. Setempat bersisipan dengan batugamping yang mengandung fosil yang menunjukkan umur Eosen. Diendapkan dalam lingkungan fluviatil sampai dengan laut dangkal, dengan ketebalan sekitar $750 \mathrm{~m}$. Dari plot peta geologi, posisi pengambilan data sangat dekat dengan formasi pitap (warna hijau).

Berdasarkan ciri - ciri batuan yang tersingkap dilapangan, daerah pengukuran berada pada batuan Pra -Tersier yaitu Formasi Pitap (Ksp) Formasi ini (warna hijau pada Gambar 6) disusun oleh perselingan antara batupasir, batulanau, serpih, rijang, breksi aneka bahan, olistolit batugamping, dan lava basal. Kenampakan dilapangan batuan ini sudah mengalami pelapukan kuat dan alterasi. Formasi ini berumur Kapur Akhir dan ketebalannya lebih dari $2.000 \mathrm{~m}$. Formasi ini menjemari dengan Formasi Haruyan diendapkan di daerah rumpang palung busur.

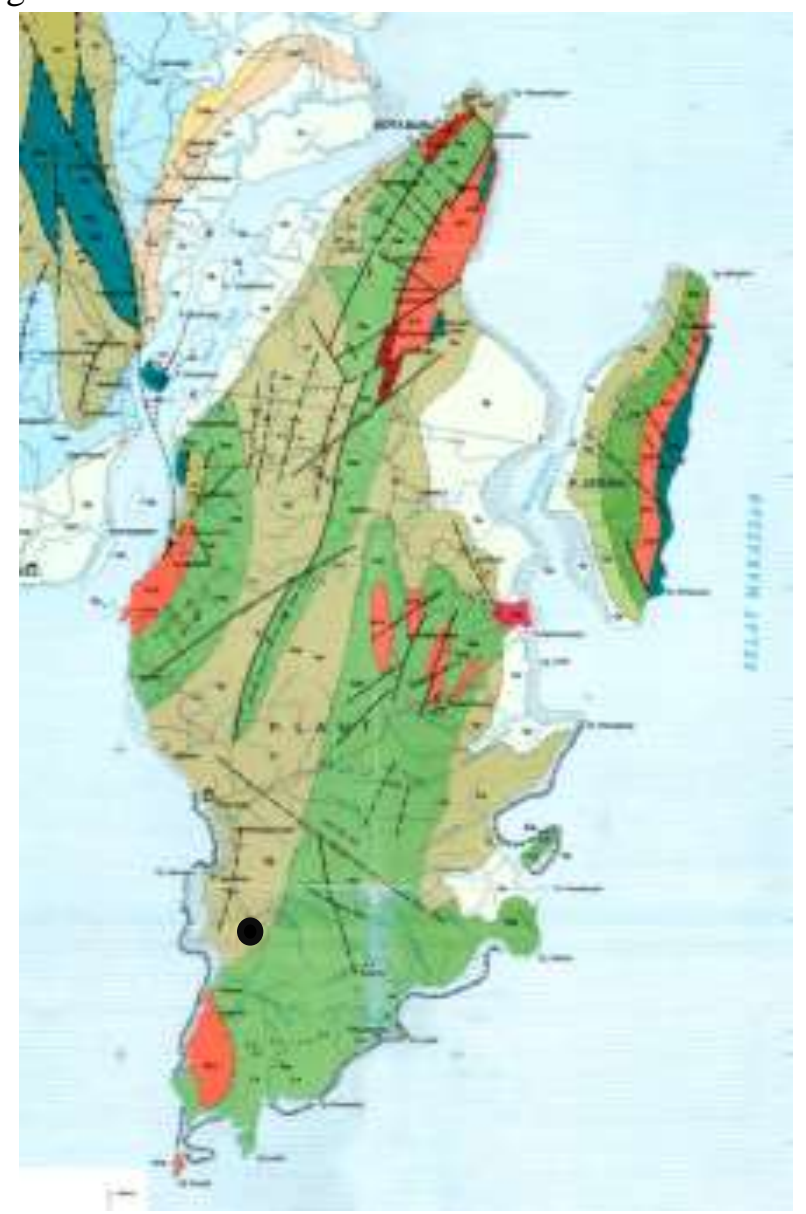

Gambar 6. Peta geologi daerah penelitian (Rustandi, dkk., 1995)

Melihat dari nilai tahanan jenisnya, maksimum hanya 140 Ohm meter. Dapat diinterpretasikan bahwa daerah pengukuran disusun 
oleh batuan Formasi Pitap yang telah mengalami pelapukan. Pada batuan yang masih fresh satuan batuan ini kompak, keras dan masif. Pada zona pelapukan, zona alterasi dan zona sesar satuan batuan ini cukup lunak. Biasanya pada zona pelapukan, alterasi dan zona sesar yang merupakan zona lemah ini akuifernya cukup produktif dibandingkan sekitarnya.

\section{Hidrogeologi}

Secara hidrogeologi regional daerah pengukuran (gambar 7) termasuk dalam daerah dengan akuifer aliran antar butir sebagian merupakan aliran antar celah. Akuifer termasuk dalam produktifitas rendah, setempat cukup berarti terutama didaerah zona sesar, zona pelapukan dan lembah-lembah, meskipun tingkat keberlanjutan produktivitas air tanahnya rendah.

Berdasarkan hasil analisa data geolistrik, daerah pengukuran masuk dalam daerah dengan akuifer batu pasir. Namun kenampakan lapisannya berbentuk bolder-bolder (Gambar 8). Hasil ini diperkuat dengan Pusdatim ESDM tahun 2020, yang menyatakan bahwa dominasi daerah penelitian adalah akuifer bercelah atau bersarang.

Secara keseluruhan berdasarkan penampang dua dimensi nilai tahanan jenis lintasan geolistrik baik dengan metode wenner -schlumberger maupun metode wenner (Gambar 8) maka dapat diinterpretasikan batuan yang menyusun di Desa Subur Makmur Kecamatan Pulau Laut Barat Kabupaten Kotabaru disusun oleh 2 (Dua) satuan batuan. Satuan batuan pertama adalah satuan batuan batupasir graywacke. Terdiri dari batupasir graywacke sisipan batulempung. Nilai tahanan jenisnya yaitu $\geq 40 \mathrm{Ohm}$ meter. Sifat hidrolika batuan ini memiliki sifat porositas yang kecil dengan permeabilitas kecil dikarenakan adanya sisipan batulempung pada akuifer, sehingga menyebabkan potensi air tanah pada satuan ini kecil. Posisi satuan batuan ini berada pada kedalaman $>40 \mathrm{~m}$. Pada penampang hasil analisa data geolistrik (Gambar 8) satuan batuan ini ditandai berwarna kuning - merah.

Satuan batuan kedua yang menyusun lintasan ini adalah satuan batuan batulempung alterasi yang terdiri dari batulempung mengandung bolder - bolder batupasir/batu beku. Nilai tahanan jenis satuan batuan ini yaitu $\leq 40 \mathrm{Ohm}$ meter. Posisi satuan batuan ini berada di permukaan hingga kedalaman sekitar $40 \mathrm{~m}$ dimana sifat hidrolika batuan ini yaitu memiliki porositas besar dengan permeabilitas sangat kecil, sehingga potensi air tanah pada satuan batuan ini sangat kecil. Pada penampang tahanan jenis (Gambar 8) satuan ini berwarna biru tua, biru dan hijau.

Merujuk dari hasil analisa data geolistik yang diperkuat data geologi dan hidrogeologi, daerah penelitian memiliki jenis akuifer batupasir yang memiliki permeabilitas rendah dikarenakan adanya sisipan batulempung. Bentuk akuifernya tidak berlapis melainkan berbentuk bolder. Hal ini kemungkinan besar diakibatkan aktivitas vulkanik pada zaman dulu di wilayah tersebut setelah terbentuknya lapisan batupasir. Akibat permeabilitasnya yang rendah menyebabkan potensi air tanah kecil di daerah pengukuran.

Selain hal tersebut, tingkat keberlanjutan ketersediaan air tanah kecil di daerah pengukuran. Hal ini dikarenakan lapisan akuifer yang berbentuk bolder yang tidak memiliki kemenerusan lapisan yang luas, sehingga menyebabkan daya tampung akuifer juga terbatas.

\section{Lokasi Titik Bor}

Daerah penelitian yang merupakan daerah yang ketersediaan air tanah yang sulit ditambah dengan daerah tersebut terdapat bolder-bolder satuan batuan yang terdapat batuan vulkanik yang sifatnya massif dan keras, sehingga penentuan akuifer dan lokasi titik sumur bor air tanah yang efektif harus benar-benar dipertimbangkan.

Dari hasil penyelidikan geolistrik terlihat adanya zona yang dapat diduga lapisan akuifer pembawa air, yaitu kedalaman $\geq 40 \mathrm{~m}$. Pada lapisan batuan yang ada di atasnya sampai ke permukaan merupakan satuan batuan batulempung. Karakteristik batuan ini akan mempersulit proses pemboran sumur bor terutama pada keadaan basah (mengandung air) yang dapat menyebabkan stank bor sulit berputar bahkan terjepit. Maka dari itu, sebaiknya jenis batuan ini di hindari.

Disisi lain, pada penampang hasil analisa geolistrik (Gambar 8) terdapat celah di permukaan yang memiliki nilai tahanan jenis mendekati nilai tahanan jenis akuifer di bawah permukaan. Dapat diinterpretasikan tidak mengandung lapisan batulempung. 


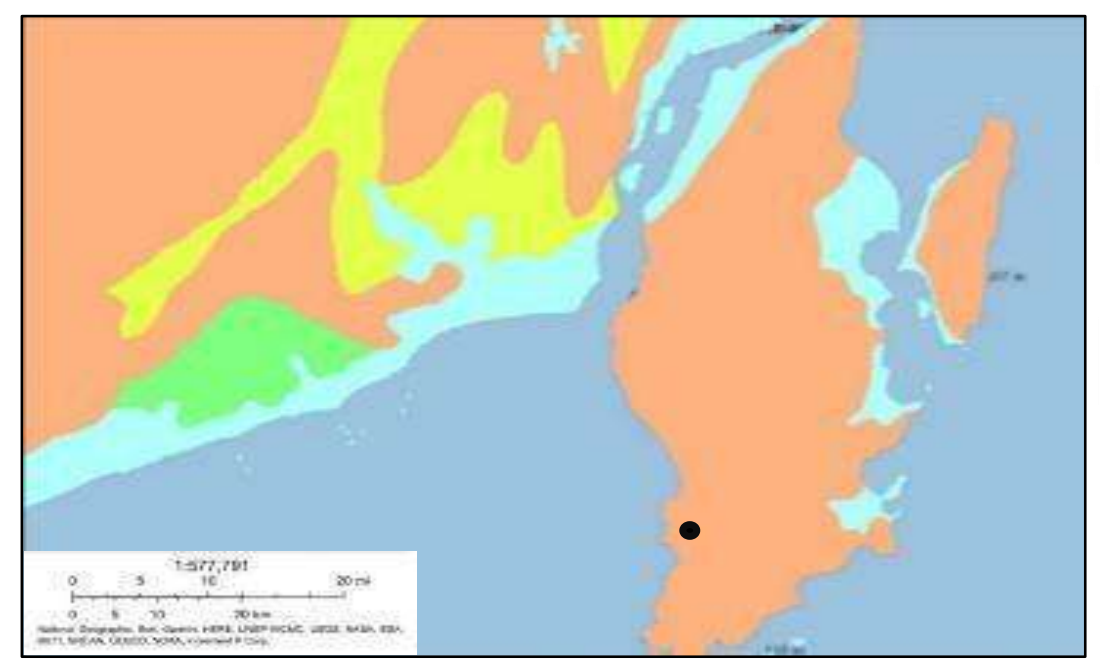

Produktivitas Akuifer

Akuifer dengan Alran Melalui Ruang Antarbutir (Akifer produktif dengan penyebaranluas?

Akuifer dengan Äliran Melalui Celahan dan Ruang Äntarbutir (Äkifer produktif sedang dengan penpebaran luas)

Akuifer dengan Aliran Melalui Ruang Rekahan dan Saluran (Setempat, akuifer produktif)

Akuifer (Bercelah atau Sarang) Produktif kecil dengan Airtanah Langka (Akuifer produktif kecil)

Gambar 7. Peta sebaran produktivitas akuifer (Pusdatin ESDM, 2020)
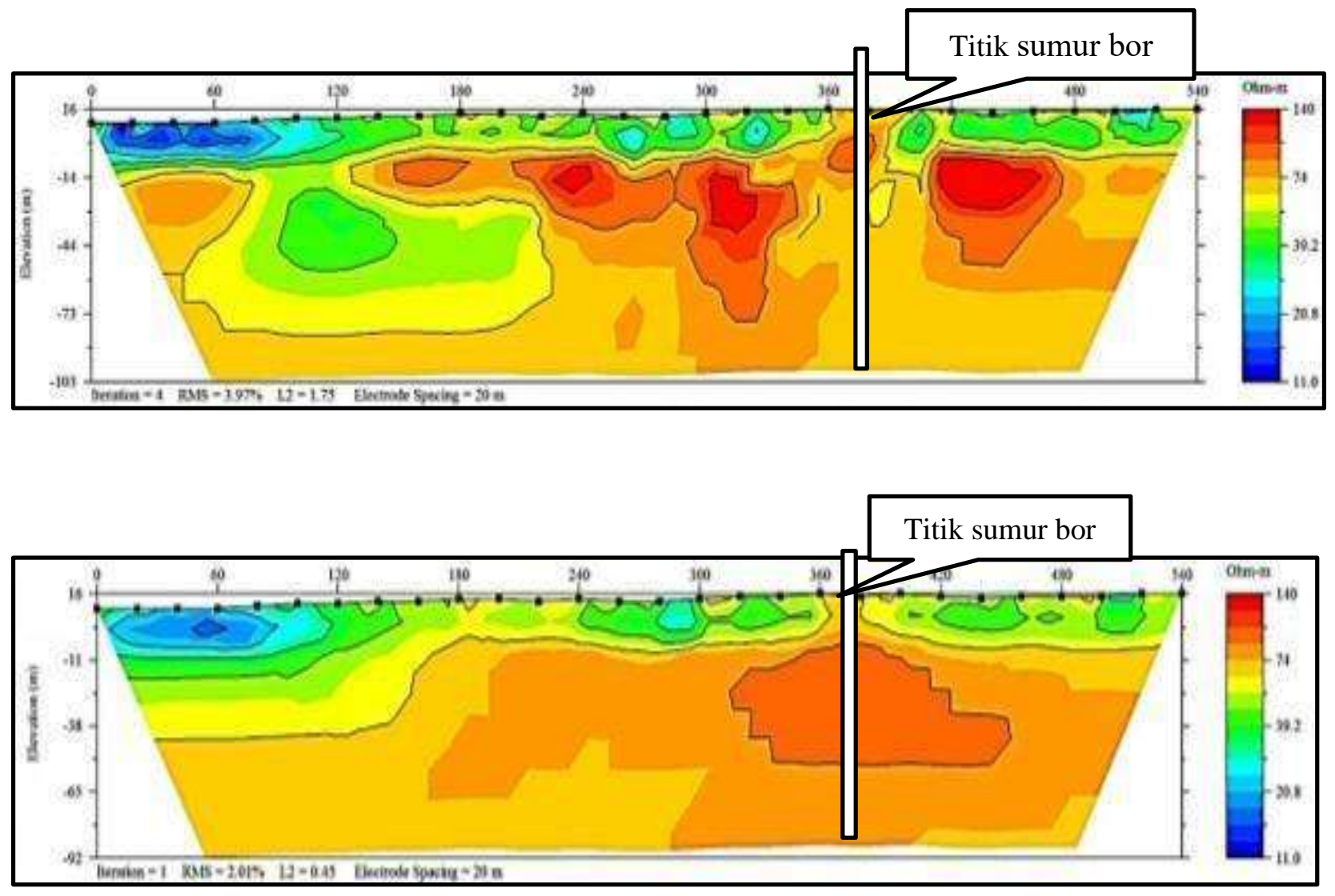

Gambar 8. Penampang geolistrik 2D Konfigurasi wenner-shlumberger (atas) dan wenner (bawah)

Hal ini terlihat pada lintasan antara 360 - 420 meter, baik pada konfigurasi wenner-schlumberger maupun wenner adanya celah yang bernilai tahanan jenis > 70 Ohm meter. Nilai ini masuk rentang tahanan jenis batuan yang mengandung air tanah (akuifer) menurut Loke tahun 2004 yaitu 10 - 100 Ohm meter. Sehingga posisi titik sumur bor yang efektif terletak di kisaran panjang lintasan antara 360 - 420 meter, dengan kedalaman pemboran sekitar 90 meter.

Penentuan Lokasi Titik Bor Air Tanah Berdasarkan Metode Tahanan Jenis 2d di Desa Subur Makmur Kabupaten Kotabaru, Kalimantan Selatan (Rudy Hendrawan Noor dan Ishaq) 


\section{KESIMPULAN DAN SARAN}

\section{Kesimpulan}

Hasil Pengamatan lapangan dan interpretasi geolistrik di lokasi penyelidikan maka didapatkan beberapa simpulan sebagai berikut:

1. Berdasarkan pengamatan di lapangan lokasi pengukuran geolistrik masuk dalam Formasi Pitap (Ksp) yang terdiri dari dari batupasir greywacke, Batulanau dan serpih.

2. Dari penampang tahanan jenis diinterpretasikan adanya dua satuan batuan yaitu satuan batuan batupasir greywacke dengan nilai tahanan jenis $\geq$ $40 \mathrm{ohm}$ meter dan satuan batuan batulempung alterasi dengan nilai tahanan jenis $\leq 40 \Omega \mathrm{m}$.

3. Posisi titik sumur bor yang efektif terletak di kisaran panjang lintasan antara 360 - 420 meter.

\section{Saran}

Mengingat kondisi geologi dan hidrogeologi serta hasil pengukuran geolistrik yang sudah dijelaskan diatas maka disarankan agar:

1. Perlu adanya penambahan pengukuran lintasan geolistrik di sekitar yang memungkinkan terdeteksi potensi air tanah yang lebih prospek.

2. Jika pemboran dilaksanakan sebaiknya dilakukan well logging setelahnya, sebagai data koreksi dari penampang tahanan jenis dan hasil pengukuran tahanan jenis di daerah sekitar.

\section{DAFTAR PUSTAKA}

Hendrajaya, L. 1990. Geolistrik Tahanan Jenis, Laboratorium Fisika Bumi. Jurusan Fisika. Fakultas Matematika dan Ilmu Pengetahuan Alam Institut Teknologi Bandung.

Loke, M.H.. 2004. Tutorial : 2-D and 3-D electrical imaging surveys.

Priyantari dan Wahyono. 2005. Penentuan Bidang Gelincir Tanah Longsor Berdasar Sifat Kelistrikan Bumi. Jurnal Ilmu Dasar 6(2):137141.

Pusat Data dan Informasi E.S.D.M. (Pusdatin ESDM). 2020. E.S.D.M. One Map: Exploring Energy and Mineral Resources of Indonesia. https://geoportal.esdm.go.id

Reynolds, J. M. 1997. An Introduction to Aplied and Environmental Geophysicsi. John Wiley and
Sons Ltd. Baffins, Chichester, West Susex PO19 IUD. England

Rustandi, E., Nila, E.S., Sanyoto, P., Margono. U.. 1995. Peta Geologi Lembar Kotabaru, Kalimantan. Pusat Penelitian dan Pengembangan Geologi.

Utiya, J., As'ari., Seni H.J.T, 2015. Metode Geolistrik Resistivitas Konfigurasi WennerSchlumberger dan Konfigurasi Dipole-dipole untuk Identifikasi Patahan Manado di Kecamatan Paaldua Kota Manado. Jurnal Ilmiah Sains Vol. 15 No. 2, Oktober 2015.

Wijaya, A. S. (2015). Aplikasi Metode Geolistrik Resistivitas Konfigurasi Wenner Untuk Menentukan Struktur Tanah di Halaman Belakang SCC ITS Surabaya.Jurnal Fisika Indonesia, 119(55): 1-5. 